\title{
Evaluation of Hospital Performance with Data Envelopment Analysis
}

\author{
Dr. Mehmet Karahan
}

Firat University

Dr. Hasan Dinç

Liaison Office by BAAINBw

\begin{abstract}
Performance evaluation provides information for lacking organizations and demonstrates how to improve performance for hospitals. Formerly, hospitals had to afford to meet the increased demand of their patients by only decreasing their operational costs. In this parallel most of the hospital was first to cut costs or avoid cases that would likely lose money. However, later health care administrators realized that the appropriate solution to keep their hospitals financially viable was to improve their performance. Efficiency analysis based on optimization techniques and their normative structure creates the benchmark for the hospitals. This is one of the most essential requirements of health care industry today. Data Envelopment Analysis (DEA) is a nonparametric linear programming technique that assesses the efficiency frontier by optimizing the weighted outputs to inputs. DEA models can provide the new solutions to increase the efficiency. DEA identifies the optimal ways of efficiency for each of the hospital rather than the averages. Since this is an appropriate way to understand the individual hospital efficiency, DEA provide the significant findings for the improvement process of hospitals. Hospitals can not only find their efficiency level, but also discover the alternative solutions to eliminate the inefficiency causes. The results of this study have also provided meaningful insights into Turkish health care managers' views of the interaction between efficiency and health care expenditures. It is expected that the findings will provide guidance for health care providers. Results also might be beneficial for other researchers in this area.
\end{abstract}

Keywords: Data envelopment analysis, efficiency analysis, hospital performance

\section{Introduction}

Health, on the one hand, is directly related to human and community life, but on the other hand it contributes to the quality of the labor factor and affects economic performance through employment and production. It is very important to know the efficiency levels of hospitals which are health sector enterprises. Because hospitals use public resources, these resources need to be used in the best way without being wasted.

Each economic unit transforms resources, inputs it procures from its external environment, into output in the form of goods and services, using a specific production technology, in order to realize its objectives. Assessing the performance of a business in a specific time period is an examination of how rational it is to transform the inputs it uses into output. In this context, when evaluating the performance of an economic unit, it is necessary to determine whether the largest output level is obtained from the inputs used, or whether the lowest output level is reached for the given output level. Here, Data Envelopment Analysis (DEA) has been developed to meet this need and to measure the relative performance of businesses.

DEA is a non-parametric efficiency measurement method that can be easily used for multiple inputs and outputs. In addition, DEA can measure by using many inputs and outputs such as cost, weight, volume. In decision-making units such as hospitals; DEA has become one of the most widely used efficiency measurement methods in recent years because a large number of different input and output variables can be used, such as number of beds, number of specialist and practitioner doctors, mortality rate, and revolving fund. 
The purpose of this study is to compare the efficiency of some selected hospitals with data envelopment analysis method. In the study, the relative efficiency of public hospitals will be analyzed in the light of factors such as the health sector's structure, organization, financing of health services and health expenditures, and proposals about health policies will be developed by making use of the results obtained. The data used in this study, in which the relative service performances of hospitals were examined, was obtained in 2015. Performance measurement based on the resource utilization efficiency of the hospitals was done by data envelopment analysis. When performance measurements were made, the hospitals were compared according to the possibilities offered by the DEA using different models, fixed scale according to the scale and variable return according to the scale. While the hospital efficiency is being calculated; Variables such as total number of beds, number of total doctors, number of nurses were used as input and number of patients treated, number of hospitalized patients, output variables. With this analysis, it is aimed to reveal the activities of hospitals to provide health services by measuring the resource utilization efficiency and performance of the hospital.

\section{Performance and Efficiency in Health businesses}

The concept of performance in general terms; Evaluation of the efforts of decision makers to achieve their goals, quantitative and qualitative explanations of what a unit of work is capable of achieving and achieving the desired outcome. In order to improve the performance of the decision-making units, it is necessary to evaluate the activities carried out in certain periods and this should be done with the generally accepted efficiency measurement methods. The main ones of these methods are classified as ratio analysis, parametric methods and non-parametric methods. The simplest and most common of the methods used to measure operating performance is the ratio analysis, which is the ratio of single entries to single outputs.

The terms productivity and efficiency, which are often used interchangeably, actually represent different economic concepts. For producers of goods or services, the concept of productivity is expressed as the ratio of the total amount of production to the total input used and has less coverage than efficiency (Caglar, 2003). The concept of efficiency, which is closely related to the concept of productivity, shows how good output can be generated from the inputs available. Efficiency is the use of resources in production at an optimal level, and some authors refer to "doing their job right" (Akal, 2000). Efficiency; Is an expression of how resources are used to provide useful output. In economical terms, the capacity to obtain the most results with the least effort and cost is technically defined as the ratio of the actual output to the maximum output (Bayraktutan and Pehlivanoglu, 2012).

The studies of efficiency in the health sector, it is noteworthy that there are more studies to estimate the technical efficiency. Technical efficiency can be defined as producing a certain amount of output by using minimum input or performing a certain production level with minimum cost. When a firm performs the same production by using less input, it should not reduce the quality and quality of the product. It can be said that the performance of a company that has achieved technical efficiency in the production process is better than that of its competitors. In the literature, it is seen that firm's performances are mostly measured by using parametric and nonparametric methods. While parametric methods are preferred when the mathematical form of the relationship between variables is known, nonparametric methods are preferred especially in the service sector such as hospitals and where the mathematical form of relationships between variables is not known precisely (Celik and Esmeray, 2014). When the literature is searched, it is seen that one of the methods frequently used in determining the technical activities of firms is the data envelopment analysis. This method is used to measure the performance of service businesses, especially hospitals that generate more than one output with multiple inputs.

Efficiency in hospital businesses is briefly related to the ability of hospitals to produce data output level (treated patient) using inputs such as personnel and financial capital. Considering that hospitals offer homogeneous services; If a hospital cannot reduce its inputs without reducing it on its output, it is technically efficient. However, if a hospital is using the same output level by using more input than other firms in the sector, it cannot use its resources efficiently.

\section{Data Envelopment Analysis}

The first applications of DEA were usually made in public institutions, ie non-profit-making businesses. Later, the method became widespread and started to be applied in profit-making enterprises. Areas of application include; Hospitals, educational institutions, military units, local governments, airports, banks, hotels and municipalities (Bowlin, 1998). Initially introduced by Charnes, Cooper and Rhodes (CCR) in 1978, DEA is a linear programming process in which a large number of inputs and outputs are used (Charnes et al., 1978). The first DEA model presented by the CCR was built on Farrell's 
work in 1957 (Cooper et al., 2004). DEA has received great interest from the following years onwards and has published a number of theoretical and practical articles and books (Tavares, 2002). DEA measures the relative efficiency of homogeneous Decision-making Units (KVAs), which produce multiple outputs using multiple inputs in a production system and perform similar tasks (Yun et al., 2004).

Data envelopment analysis is a technique in which some mathematical programming methods are used to compare the relative efficiency of units in a group. These units are often called decision-making unit. The most important advantage of DEA is that it does not require any functional connection assumption between input and output. This advantage gives DEA a nonparametric method (Ayricay and Ozcalici, 2014). DEA is a special application of linear programming, which is commonly used to measure the relative efficiency of businesses with the same objectives and targets operating in the service sector (Tunca et al., 2010). DEA is a method used to measure the relative efficiency of businesses with the same goals and objectives. Areas of application of DEA; hospitals, banks, courts, schools, etc. institutions (Tetik, 2003).

The DEA method is often used to measure the effectiveness of a large number of units, such as production units, banks or hospitals, characterized by complex input and output. Efficiency and efficiency analyzes are crucial management tools in determining the extent to which inputs are used in the process of obtaining desired output. In DEA, the units that are evaluated are called decision-making units and the performance measurement is done in these input and output units. DEA is a useful method especially when the relations between input and output are unknown. The first model (CCR) developed by Charnes, Cooper and Rhodes under the assumption of Constant to Return Scale was later arranged by the Banker, Charnes, Cooper in the form of Variable Return to Scale, giving a new dimension to efficiency measurement. This form of DEA is referred to as the BCC model (Karahan and Akdag, 2014). DEA is a non-parametric, linear programming method that provides a powerful comparison method that measures the relative activities of decision-making units in a large number of input and output organizations, evaluating their efficiency. In this sense, RIA is considered as a multi-criteria decisionmaking (MCDM) technique. In the service process, a large number of outputs are usually obtained using a large number of inputs. Having a feature that considers all inputs and outputs without choosing a successful service is a superior aspect of DEA's other productivity analyzes (Aslan and Mete, 2007).

DEA is a mathematical programming-based technique used to measure the relative activities of organizational units with multiple inputs / outputs that do similar work. Data envelopment analysis is considered to be an effective approach, especially in situations where more than one input field cannot be converted into a weighted input or output set. DEA considers the best observation as the efficiency limit. After this determination, other observations are evaluated according to this most effective observation. On the other hand, the dual of each model is created and analyzed. The reasons for inactive units are determined and what is to be done in the input and output to be effective. Data envelopment analysis differs from other methods in describing optimal performance instead of performance averages (Guzel et al., 2012).

\section{Hospital Efficiency Case Study}

The main purpose of this study is to determine the activities / performances of the health institutions by measuring the input usage efficiency of the hospitals operating in Turkey. One of the aims of the study is to develop policy recommendations to improve health care services by comparing the effectiveness of hospitals. In this study, the efficiency of hospitals, outputoriented approach of data envelopment analysis method, constant return by scale, variable return by scale and scale efficiency indices were calculated. When the calculation was made, all the hospitals were evaluated together, the effectiveness values were measured, then the incomplete or redundant of the inactive hospitals were determined and finally, what was needed to improve the performance of the hospitals determined to be ineffective. In this context, total, technical and scale efficiency were calculated by evaluating data of 9 hospitals operating in Turkey. Utilizing the findings, the output needed to increase and the amount of inputs that need to be reduced have been determined so that hospitals that are not actively working can work more efficiently and resource waste is avoided.

\subsection{Research Methods and Data Used}

In the study, DEA was used to measure the efficiency of the hospitals. The most important reason for choosing this method is that it can be easily used for multiple inputs and outputs. DEA uses all the data, does not exclude any data and can be used without problems. Therefore, the most possible input and output variables were tried to be created by taking into consideration the fields of activity of the hospitals and the related literature. Since revolving fund data for hospitals, budget allocations and expenditure data cannot be supplied, they cannot be used as variables. Input and output variables affecting 
hospital performance are taken from Ministry of Health 2015 data. Essentially, there are a large number of input and output variables in hospital enterprises. However, outcome variables are the number of patient controls performed at the hospital. Likewise, as input variables, the number of beds and the number of human resources are considered. In the distribution of resources to the hospitals, as the number of beds is taken as the basis, the number of beds is considered as input variables by considering many input variables.

Input variables in the study; total number of beds, total number of doctors, number of nurses. The output is variable; number of patients treated, number of hospitalized patients.

The number of variables must be kept as limited as possible, since the ability of the DEA to decompose in the case of too many inputs and outputs to the application drops. The sum of inputs and outputs should be less than the number of decision units (Aslan and Mete, 2007). For this reason, in this study, the sum of input and output units is kept less than the number of decision units. The data used in the analyzes were handled on an annual basis and it was taken into consideration that sample hospitals were selected and they were similar to each other in service production. Thus, the best production limit was set for 9 hospitals and performance indicators were evaluated according to this class. Data envelopment analysis and efficiency studies were conducted using the WinDEAP 2.1. package program.

\subsection{Findings of the study}

The technical efficiency scores calculated by the DEA range from 0 to 1 . As these values approach 1 , the efficiency increases, and the zero approach decreases the effectiveness. When the technical efficiency score is 1 , there is full technical efficiency. This shows that the active hospital is at the best production limit. For this purpose, since the efficacy score is compared to the value of 1 , the ineffectiveness scores are less than 1 . This score (1-activity score) can be calculated as. If the technical efficiency index value is less than 1 , it indicates that the operator cannot produce maximum output with his current inputs. In other words, this means that the actual output of the operator can be generated with less input. In Table 1 below, five hospitals with less than the technical efficacy level 1 (ineffective) were identified.

\subsubsection{Sample Hospitals Efficiency Scores}

Table 2 shows the input-oriented technical efficiency, pure efficiency and scale efficiency scores of 9 hospitals operating in Turkey.

Table 1: Efficacy Scores of 9 Hospitals

\begin{tabular}{|l|l|l|l|l|l|l|l|}
\hline Hospitals & $\begin{array}{l}\text { Technical } \\
\text { Efficiency } \\
\text { (CRS) }\end{array}$ & $\begin{array}{l}\text { Pure Efficiency } \\
\text { Value } \\
\text { (VRS) }\end{array}$ & \multicolumn{2}{l|}{ Scale Efficiency } & \multicolumn{2}{l|}{$\begin{array}{l}\text { Reference } \\
\text { Set }\end{array}$} & $\begin{array}{l}\text { Reference } \\
\text { Number }\end{array}$ \\
\hline 1 & 0.375 & 0.424 & 0.884 & irs $^{*}$ & $\mathbf{5 ( 0 . 5 9 2 )}$ & 1 \\
\hline 2 & 1.00 & 1.00 & 1.00 & - & - & 0 \\
\hline 3 & 0.515 & 0.519 & 0.993 & irs $^{*}$ & $\mathbf{4}(\mathbf{0 . 6 4 2}), \mathbf{5}(\mathbf{0 . 3 0 6})$ & 2 \\
\hline 4 & 1.00 & 1.00 & 1.00 & - & - & 0 \\
\hline 5 & 1.00 & 1.00 & 1.00 & - & - & 0 \\
\hline 6 & 0.684 & 1.00 & 0.684 & irs $^{*}$ & $\mathbf{8}(0.014), 4(0.176)$ & 2 \\
\hline 7 & 0.635 & 1.00 & 0.635 & irs $^{*}$ & $\mathbf{2 ( 0 . 0 1 7 ) , 8 ( 0 . 2 7 6 ) , 4 ( 0 . 0 3 0 )}$ & 3 \\
\hline 8 & 1.00 & 1.00 & 1.00 & - & - & 0 \\
\hline 9 & 0.460 & 0.800 & 0.575 & irs $^{*}$ & $\mathbf{4}(\mathbf{0 . 1 5 3 )}$ & 1 \\
\hline
\end{tabular}

*increasing return to scale

According to the results of the analysis made in Table 1, it is seen that the efficiency results of 9 hospitals are effective in CRS 4 hospital $(2,4,5,8)$ and 5 hospitals $(1,3,6,7,9)$ are not effective. According to VRS 6 hospitals seem to be effective. In scale efficiency, the results in CRS are equal to each other.

As shown in Table 1, the values in the reference set are used to make ineffective hospitals effective, and the input or output values that the hospital needs to increase or decrease are calculated by the package program. According to the analysis results, it was determined that 5 of 9 hospitals did not work effectively. These are hospitals numbered 1, 3, 6, 7 and 9 . In 
order to make these five hospitals effective, the adjustments to be made in the input and output variables were calculated by means of the DEAP 2.1 program and the results obtained are shown below in separate tables for each of the five hospitals.

\subsubsection{Corrections Required to Enable Inefficient Hospitals}

As a result of the analyzes made on 9 hospitals, the five hospitals that were determined not to work effectively had to make necessary adjustments in order to be able to work effectively and the corrections to be made in the variables of the 1 st hospital were shown in Table 2 below.

Table 2: Amounts Needed to Increase / Reduce Hospital Number One

\begin{tabular}{|l|l|l|l|l|}
\hline Hospital 1 & Current Value & Target Value & Required Increase & Required Reduction \\
\hline Number of Patients Treated & 4637 & 14537 & 9900 & - \\
\hline Number of Patients Hospitalized & 10356 & 10356 & - & - \\
\hline Total Number of Beds & 150 & 56 & - & 94 \\
\hline Total Number of Doctors & 90 & 82 & - & 8 \\
\hline Number of Nurses & 144 & 12 & - & 132 \\
\hline
\end{tabular}

As seen in Table 2, the number of patients treated in the first hospital should be increased by 9900 , there is no need to change the number of patients hospitalized, total number of beds should be reduced by 94 , total number of doctors should be reduced by 8 , the number of nurses should be reduced by 132 person.

As a result of the analysis made, the program needs to be adjusted so that the hospital No. 3 , which is determined not to be effective, can work effectively. The adjustments to be made in the variables of the 3th hospital patient are shown in Table 3 below.

Table 3: Amounts Needed to Increase / Reduce Hospital Number Three

\begin{tabular}{|l|l|l|l|l|}
\hline Hospital 3 & Current Value & Target Value & Required Increase & Required Reduction \\
\hline Number of Patients Treated & 30944 & 30944 & - & - \\
\hline Number of Patients Hospitalized & 9765 & 9765 & - & - \\
\hline Total Number of Beds & 150 & 77 & - & 73 \\
\hline Total Number of Doctors & 75 & 29 & - & 46 \\
\hline Number of Nurses & 135 & 68 & - & 67 \\
\hline
\end{tabular}

As shown in Table 3, hospital number three; total number of beds should be reduced by 73 , total number of doctors should be reduced by 46 , and number of nurses should be reduced by 67 .

As a result of the analyzes made, the necessary corrections are made by the program in order to enable the 6th hospital that is not working effectively to function effectively. The corrections to be made in the variables of the 6th hospital are shown in Table 4 below.

Table 4: Amounts Needed to Increase / Reduce Number Six Hospital

\begin{tabular}{|l|l|l|l|l|}
\hline Hospital 6 & Current Value & Target Value & Required Increase & Required Reduction \\
\hline Number of Patients Treated & 6601 & 6601 & - & - \\
\hline Number of Patients Hospitalized & 449 & 1232 & 783 & - \\
\hline Total Number of Beds & 20 & 14 & - & 6 \\
\hline Total Number of Doctors & 16 & 7 & - & 9 \\
\hline Number of Nurses & 25 & 17 & - & 8 \\
\hline
\end{tabular}

As seen in Table 4; there should be no change in the number of patients treated, the number of inpatient patients should be increased by 783 , the number of total beds should be reduced by 6 , the number of total doctors should be reduced by 9 , and the number of nurses should be reduced by 8 . 
As a result of the analyzes made, the necessary corrections are made by the program in order to enable the 7th hospital that is not working effectively to function effectively. The corrections to be made in the variables of the 7 th hospital are shown in Table 5 below.

Table 5: Amounts Needed to Increase / Reduce Number Seven Hospital

\begin{tabular}{|l|l|l|l|l|}
\hline Hospital 7 & Current Value & Target Value & Required Increase & Required Reduction \\
\hline Number of Patients Treated & 5318 & 5318 & - & - \\
\hline Number of Patients Hospitalized & 591 & 931 & 340 & - \\
\hline Total Number of Beds & 24 & 15 & - & 9 \\
\hline Total Number of Doctors & 7 & 4 & - & 3 \\
\hline Number of Nurses & 11 & 7 & - & 4 \\
\hline
\end{tabular}

As seen in Table 5; there should be no change in the number of patients treated, the number of patients hospitalized should be increased by 340 , the number of total beds should be reduced by 9 , the number of total doctors should be reduced by 3 , and the number of nurses should be reduced by 4 .

As a result of the analyzes made, the necessary corrections are made by the program in order to enable the 9th hospital that is not working effectively to function effectively. The corrections to be made in the variables of the 9th hospital are shown in Table 6 below.

Table 6: Amounts Needed to Increase / Reduce Number Nine Hospital

\begin{tabular}{|l|l|l|l|l|}
\hline Hospital 9 & Current Value & Target Value & Required Increase & Required Reduction \\
\hline Number of Patients Treated & 5595 & 5595 & - & - \\
\hline Number of Patients Hospitalized & 80 & 1053 & 973 & - \\
\hline Total Number of Beds & 25 & 11 & - & 14 \\
\hline Total Number of Doctors & 38 & 6 & - & 32 \\
\hline Number of Nurses & 79 & 15 & - & 64 \\
\hline
\end{tabular}

As seen in Table 6; there should be no change in the number of patients treated, the number of patients hospitalized should be increased by 973 , the number of total beds should be reduced by 14 , the number of total doctors should be reduced by 32 , and the number of nurses should be reduced by 64 .

\section{Results}

Institutions that provide health care services which are critical with respect to quality of human life and labor productivity need to be managed with an understanding of efficiency. It is an important requirement that hospitals offering community health services operate effectively, gain competitive advantage by providing cost advantage, and show continuity in the sector. This issue has become increasingly important, especially as the private health institutions, which have increased rapidly and developed as alternative to public hospitals in our country. Private healthcare providers have become the competitors of public enterprises, especially university hospitals, as they are comparable to each other in the marketplace, offering cheaper quality health care.

In this study, technical efficacy of 9 hospitals operating in Turkey and providing similar services was measured by data envelopment analysis. 4 of the hospitals were effective, 5 of them were not effective. Technically effective enterprises, have a cost advantage over ineffective businesses in the sector. From the point of view of cost advantage, it is not possible for health enterprises which cannot produce technically efficient services to operate in this sector for a long time. For this reason, these firms are obliged to increase their service output in a certain amount of input in the following periods. The increase in the number of technically effective firms in the sector means that similar services on the market can be cheaper. In this case, competition in the sector will also increase. The increase in similar studies in the following years will increase the efficiency of the hospitals as well as the competition in the sector and this competition will be more beneficial to the beneficiaries.

In the study, the values of the input or output that the hospital needs to increase in increments of the hospital are calculated by the package program using the values in the reference set so that inactive hospitals can be activated. As a result of the analysis, 5 hospitals were found to be inactive. These are hospitals numbered 1,3,6,7 and 9 , and the corrections to be made in the input and output variables are shown below. 
Number 1 hospital; the number of patients treated should be increased by 9900 . No change in the number of patients hospitalized. The total number of beds must be reduced by 94 . The number of total doctor should be reduced by 8 . The number of nurses must be reduced by 132 .

Number 3 hospital; no change in the number of patients treated and the number of patients hospitalized. The total number of beds must be reduced by 73 . The number of total doctors should be reduced by 46 . The number of nurses must be reduced by 67 .

Number 6 hospital; no change in the number of patients treated. The number of patients hospitalized should be increased by 783 . The total number of beds must be reduced by 6 . The number of total doctors should be reduced by 9 . The number of nurses must be reduced by 8 .

Number 7 hospital; no change in the number of patients treated. The number of patients hospitalized should be increased by 340 . The total number of beds must be reduced by 9 . The number of total doctors should be reduced by 3 . The number of nurses must be reduced by 4 .

Number 9 hospital; no change in the number of patients treated. The number of patients hospitalized should be increased by 973 . The total number of beds must be reduced by 14 . The number of total doctors should be reduced by 32 . The number of nurses must be reduced by 64 .

\section{References}

[1] Akal, Z. (2000). Performance Measurement and Control in Operations Multidimensional Performance Indicators, MPM, No: 473, Ankara.

[2] Aslan, S. and Mete, M. (2007). Data Envelopment Analysis Method in Performance Measurement: The Case of Birth and Children Hospitals Dependent on the Ministry of Health, IU, Business Administration Journal of Business Administration, April 2007, Vol. 36, No. 1, pp. 44-63.

[3] Ayricay, Y. and Ozcalici, M. (2014). Between the years of 1997-2012 in Turkey DEA Related Published Studies of Academic, KSU, IIBF Journal, Volume 4, Issue 1, pp. 246-279.

[4] Bayraktutan, Y. and Pehlivanoglu, F. (2012). Efficiency Analysis in Health Establishments: Kocaeli example, Kocaeli University Journal of Social Sciences Institute, Volume: 23, p.127-162.

[5] Bowlin, W. F. (1998). "Measuring Performance: An Introduction to Data Envelopment Analysis (DEA)", The Journal of Cost Analysis, p.3-27.

[6] Charnes, A., Cooper, W.W., Rhodes, E. (1978). "Measuring the efficiency of decision making units", European Journal of Operation Research, Volume: 2, p.429-444.

[7] Cooper, W.W., Seiford, L. M., Zhu, J. (2004). Handbook on Data Envelopment Analysis, Kluwer Academic Publishers, Boston.

[8] Caglar, A. (2003). Efficiency Measurement of Municipalities by Data Envelopment Analysis, Doctorate Thesis, Hacettepe University Institute of Science, Department of Statistics, Ankara.

[9] Celik, T. and Esmeray, A. (2014). Measurement of Cost Efficiency in Private Hospitals in Kayseri by Data Envelopment Method, International Alanya Business Administration Journal, Vol: 6, №: 2, p.45-54.

[10] Guzel, D., Celik, A. K., Akbaba, A.I. (2012). Relevant Efficiency Analysis of University and State Hospitals in Erzurum with Data Envelopment Method, 12th Production Research Symposium - UAS 2012, Izmir, Procedings Book, p.975-981.

[11] Karahan, M. and Akdag, R. (2014). Measurement of Service Activity by Data Envelopment Analysis: Diyarbakir DISKI Example, Journal of Selcuk University Social Sciences Institute, Dr. Mehmet YILDIZ Special Issue.

[12] Tavares, G. (2002). A Bibliography of Data Envelopment Analysis (1978-2001), Rutcor Research Report, 01-02.

[13] Tetik, S. (2003). Data Envelopment Analysis in Determining Operational Performance, Celal Bayar University, Faculty of Economics and Administrative Sciences, Volume: 10, No: 2, p.221-229, Manisa, Turkey.

[14] Tunca, M. Z., Omurbek, N. and Bal, V. (2010). Measurement of Efficiency in Training and Research Hospitals with Data Envelopment Analysis, 10th National Production Research Symposium, 16 - 18 September 2010, Procedings Book, p.1-8. Girne, KKTC.

[15] Yun, Y. B., Nakayama, H., and Tanino, T. (2004). A Generalized Model for Data Envelopment Analysis, European Journal of Operational Research, Volume: 157, p.87-105. 